MIRELLA CLAUSI ${ }^{\mathrm{a}}$ - DIEGO LEONE ${ }^{\mathrm{a}}$ - SERGEI E. SPIRIDONOV ${ }^{\mathrm{b}}$

\title{
HAPLOTYPE DIVERSITY OF STEINERNEMA FELTIAE (NEMATODA: STEINERNEMATIDAE) IN EURASIA (1)
}

\author{
a) Department of Biological, Geological and Environmental Sciences, University of Catania, \\ Via Androne, 81, Catania, CT 95124, Italy; \\ b) Centre of Parasitology, A.N. Severtsov Institute of Ecology and Evolution, Russian Academy of Sciences, \\ Leninskii Prospect, 33, 119071, Moscow, Russia \\ Corresponding Author: Mirella Clausi: mclausi@unict.it
}

Clausi M., Leone D., Spiridonov S.E. - Haplotype diversity of Steinernema feltiae (Nematoda: Steinernematidae) in Eurasia.

Phylogenetic analysis of ITS rDNA sequences of the entomopathogenic nematode Steinernema feltiae Filipjev, 1934 (Wouts, Mráček, Gerdin and Bedding, 1982) was used to infer intraspecific genetic variability of this rhabditid nematode. Nucleotide intraspecific differences among S. feltiae isolates reached the level of 19 base pairs per ITS rDNA region, i.e. up to $2.9 \%$. Several weakly or moderately supported intraspecific clades were detected. Sicilian and Swiss isolates of S. feltiae were found clustering together. Swiss strain 'St. Bernard' has been isolated on the St. Bernardino mountain pass in Switzerland in 2000. Phylogenetic relationships among S. feltiae isolates were inferred by using three different methods (maximum parsimony, neighbor joining and maximum likelihood). The topologies of the phylogenetic trees were identical and thus only ML tree is presented. ML tree revealed that $S$. feltiae isolates from Israel and Armenia grouped at the basal position of the tree, while in the spanning network obtained with POPART software, Iranian and Ukrainian isolates were the closest to the outgroup. In all methods of analyses, the European and Siberian strains of $S$. feltiae occupied terminal positions. Thus, further studies on the intraspecific genetic variability of entomopathogenic nematodes is needed.

KEY WORDS: insect pathogens, ITS rDNA, nucleotide diversity, soil nematodes.

\section{INTRODUCTION}

The representatives of two families of rhabditids, Heterorhabditidae and Steinernematidae, are ecologically similar soil-inhabiting nematodes, which can attack and kill soil-borne insects. These so-called entomopathogenic nematodes (EPN) can be used against insect pests of agriculture and forestry. Despite several decades of intensive studies, the population structure of EPN species in nature and their life habits in the soil are still little known. There are several very widespread, nearly co-smopolitan, species among EPN, and Steinernema feltiae Filipjev, 1934 (Wouts, Mráček, Gerdin and Bedding, 1982) is one of such species now recorded in nearly all continents. Within S. feltiae, several intraspecific groups or haplotypes can be distinguished based on nucleotide differences in the sequences of variable loci. Though intensive sampling is still necessary for representative mapping of $S$. feltiae strains throughout the globe, some geographical patterns in the distribution of separate haplotypes are already obvious.

\section{MATERIALS AND METHODS}

Soil samples were collected in Catania region of Sicily (Italia) and tested for the presence of the entomopathogenic nematodes using Galleria bait method as it was described before (CLAUSI et al., 2011, 2017). DNA was extracted from single or several juveniles (5-11 individuals) with proteinase $\mathrm{K}$ according to HOLTERMAN et al. (2006). PCR reactions were performed using Encyclo Plus PCR kit (Evrogen ${ }^{\circledR}$, Moscow, Russia) according to the manufacturer's manual. Two pairs of primers were used for amplification of ITS rDNA region: those proposed by CURRAN \& DRIVER (1994): TW81 (GTT TCC GTA GGT GAA CCT GC) - AB28 (ATA TGC TTA AGT TCA GCG GGT) and the primers of VRAIN ET AL. (1992): Vrain_F (TTG ATT ACG TCC CTG CCC TTT) and Vrain_R (TTT CAC TCG CCG TTA CTA AGG). PCR cycling parameters recommended by these authors were used: primary denaturation at $94^{\circ} \mathrm{C}$ for 3 min; 34 cycles $94^{\circ} \mathrm{C}$ for $30 \mathrm{~s}, 55^{\circ} \mathrm{C}$ for $30 \mathrm{~s}$ and $72^{\circ} \mathrm{C}$ for $1 \mathrm{~min}$, and post-amplification extension at $72^{\circ} \mathrm{C}$ for 5 min. PCR reaction products were visualised in agarose gel, bands excised for DNA extraction with Wizard SV Gel and PCR Clean-Up System (Promega, Madison, USA). Samples were directly sequenced. Three isolates of $S$. feltiae isolated in the Etna area and designated as Sant'Alfio, \#45 and Pietracannone were found to be identical in ITS rDNA sequence. Therefore, only the latter sequence was deposited in NCBI GenBank as MT830907. The sequences with high nucleotide similarity with $S$. feltiae were searched for in NCBI GenBank using BLAST algorithm (ALTSCHUL et al., 1990). Clustal_X (THOMPSON et al., 1997) was used to generate the alignments under default values for gap opening and gap extension penalties. PAUP* $4.0 \mathrm{~b} 10$ (SWOFFORD, 1998) and MEGA 7.0.14 (KUMAR et al., 2016) were used to

Original scientific contribution presented and discussed at the XIII National Congres

of the Italian Society of Nematology (SIN), Catania - Italy, October 2-4, 2019.

Received 10 August $2020 \quad$ Accepted 8 October 2020 
infer phylogeny and estimate the nucleotide differences with three methods of analysis (Maximum Parsimony - MP; Neighbour Joining - NJ; and Maximum Likelihood - ML). Obtained alignments were also used for construction of phylogenetic network using statistical parsimony (SP) as implemented in POPART software (http://popart.otago.ac.nz) (BANDELT et al., 1999).

\section{RESULTS}

BLAST search at NCBI identified 38 sequences of $S$. feltiae with high level of similarity with Sicilian ones. Some of these downloaded sequences were identical or showing differences in few nucleotides between each other. Such repetitive sequences were excluded from analysis. Totally, 18 sequences of $S$. feltiae ITS rDNA region were analysed and the taxonomically closest $S$. weiseri was used as an outgroup (Table 1). The phylograms obtained with the three different methods were nearly identical, and the ML phylogram is presented in this paper with the values of bootstrap support of all three methods presented at the nodes (Fig. I). Steinernema feltiae sequences from Sicily were identical with those deposited in NCBI GenBank as GU599911 and GU599912. The latter sequences were significantly shorter (332 and $331 \mathrm{bp}$ ) than ours, containing only ITS1+5.8S rDNA and thus were excluded from further analysis. A phylogenetic network for the ITS sequences reconstructed using statistical parsimony with POPART software demonstrated the complex structure of $S$. feltiae species (Fig. II). The number of nucleotide differences between haplotypes according to statistical parsimony analysis was also estimated with Popart (Fig. II).

\section{DISCUSSION}

The genus Steinernema Travassos, 1927 accounts for slightly less than one hundred of described species. Molecular and phylogenetic analyses along with morphological characters, supported the existence of different species (NGUYEN et al., 2001; STOCK et al., 2001; SPIRIDONOV et al., 2004). Different level of intraspecific nucleotide variability has been found in Steinernema species. As to $S$. feltiae, sequence analyses of ITS among the different isolates have demonstrated the presence of intraspecific nucleotide variation on the level of a $2.5 \%$ percentage of nucleotide differences (SPIRIDONOV et al., 2004). We can note here that the nucleotide difference between Sicilian $S$. feltiae and two closest isolates ( $\mathrm{St}$. Bernardino and UK A1) is $3 \mathrm{bp}$. The level of differences with all other isolates is higher (Fig. II). The topologies of the phylogenetic trees obtained by using the three methods, were identical in grouping $S$. feltiae isolates (Fig. I). The level of bootstrap-support for nearly all the internal groupings of $S$. feltiae was weak or moderate except for the grouping containing the topotype from Izhevsk (Russia) and the grouping consisting of Swiss and Sicilian isolates moderately supported (82-86\%). Close relationships of Swiss and Sicilian isolates was also evident in the spanning network (Fig. II). In the phylogenetic tree, the isolates from Armenia and Israel were in the basal position (with the closest relationships with the outgroup $S$. weiseri), indeed in spanning network, the isolates from Ukraine and Iran were located at the basal position. It is very interesting to point out that all these isolates originated from the same area, Middle East - Black Sea region

Table 1 - The list of ITS rDNA sequences of Steinernema feltiae isolates used in the final analysis: origin and accession numbers.

\begin{tabular}{|l|l|c|c|}
\hline \hline & Isolate & Country & Accession number \\
\hline 1 & DONR & Ukraine & KF939329 \\
\hline 2 & Hamadan & Iran & JN098450 \\
\hline 3 & Artybash, Altai & Russia & AY171272 \\
\hline 4 & KChR (Caucasus 1) & Russia & MT830903 \\
\hline 5 & Elbrus (Caucasus 2) & Russia & MT830904 \\
\hline 6 & Sakhalin, Sovetskoye & Russia & MT830906 \\
\hline 7 & Jakutia & Russia & KM016419 \\
\hline 8 & Hokkaido & Japan & AY238178 \\
\hline 9 & Khosrov & Armenia & AY171256 \\
\hline 10 & Kinneret & Israel & MT830905 \\
\hline 11 & 'A1', site 76 & UK & AY230169 \\
\hline 12 & 'A2', site 107 & UK & AY230170 \\
\hline 13 & Belgium 2 $N$ AY171256 \\
\hline 14 & Belgium 1 Va & Belgium & AY171274 \\
\hline 15 & Pietracannone & Belgium & MT830907 \\
\hline 16 & St. Bernard & Italy & AY171247 \\
\hline 17 & Tomsk & Switzerland & AY171273 \\
\hline 18 & Izhevsk, topotype & Russia & AY171246 \\
\hline
\end{tabular}




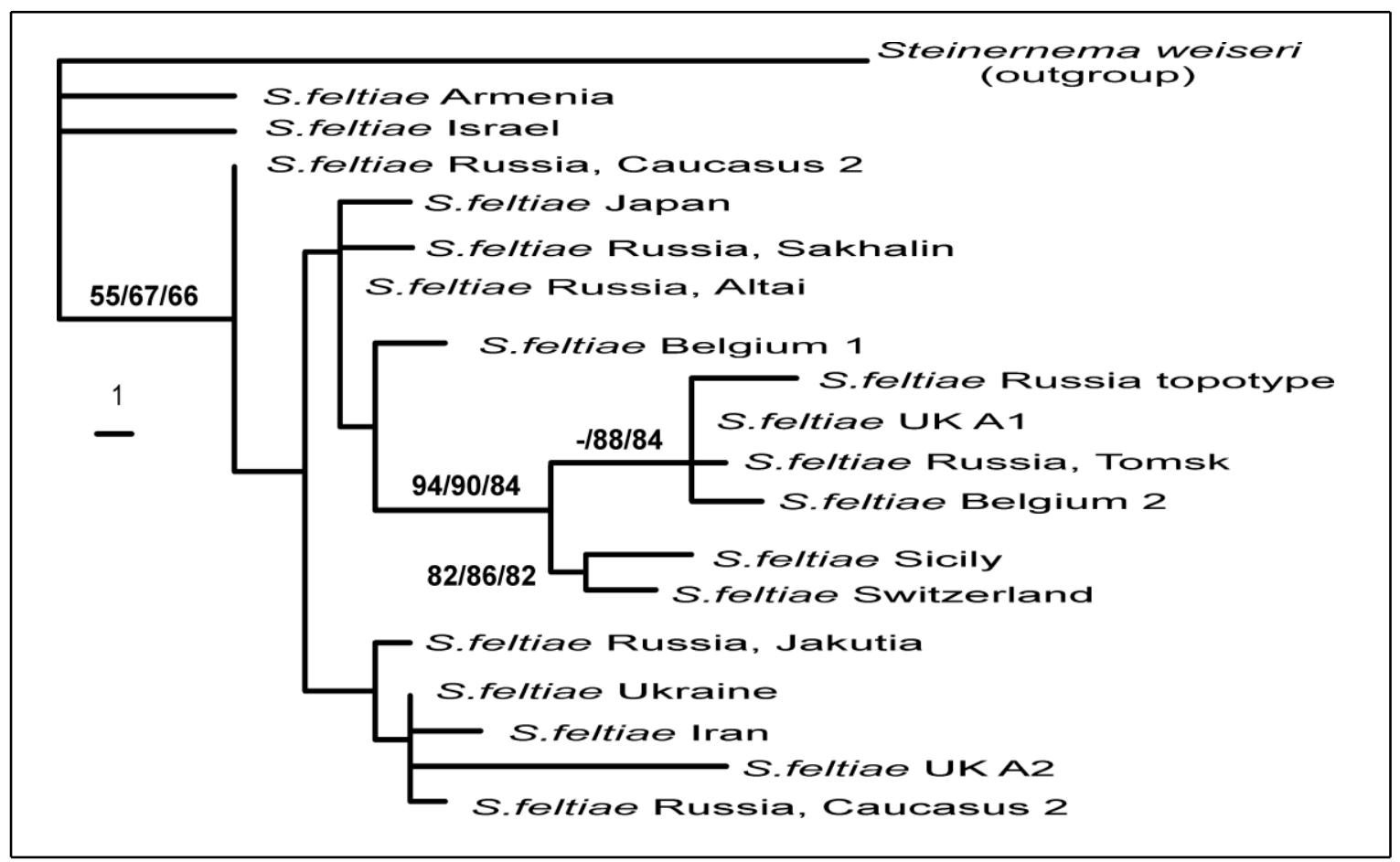

Fig. I - Phylogenetic relationships within Steinernema feltiae as inferred from analyses of the ITS rDNA sequences. The values of bootstrap support near nodes are given in format MP/NJ/ML.

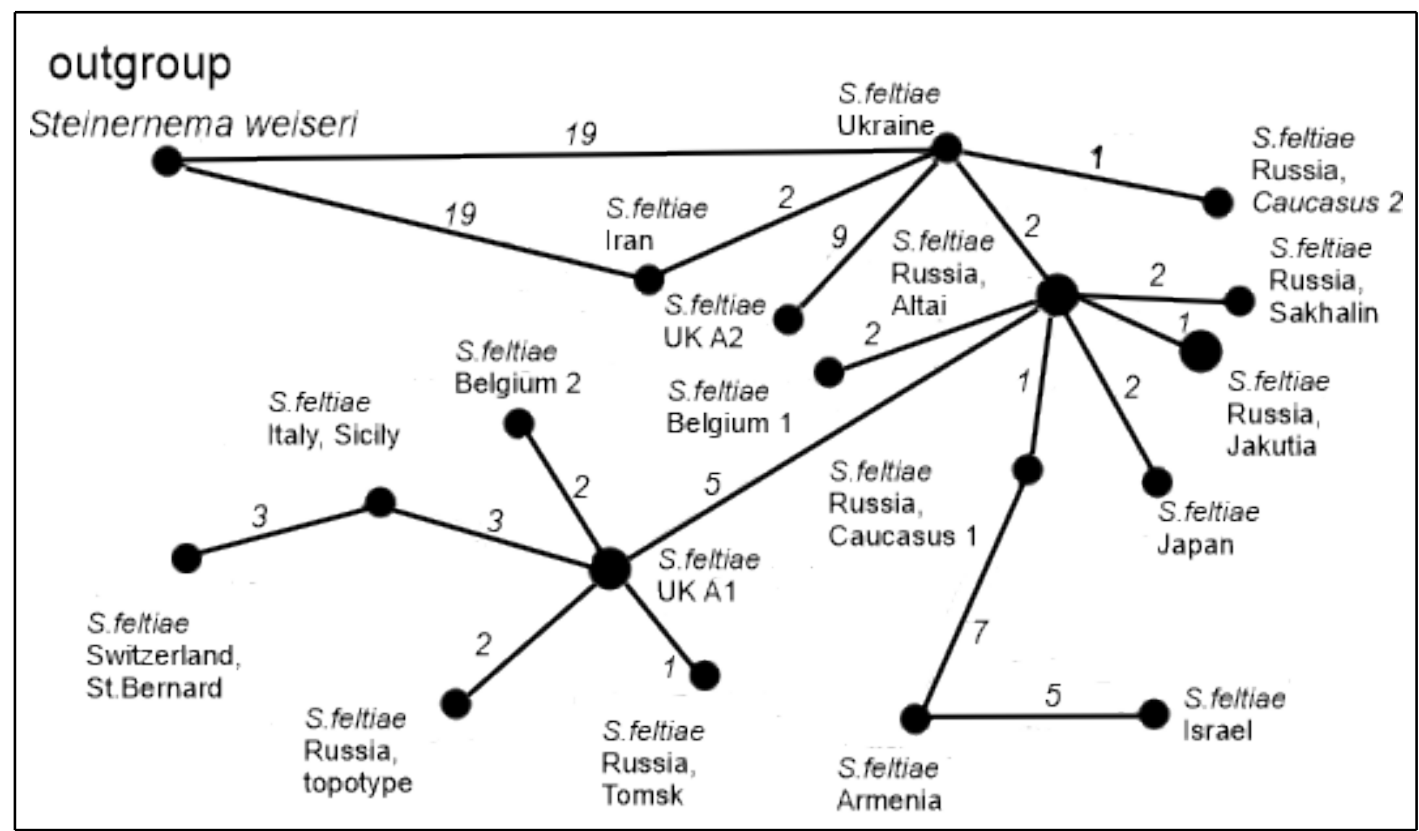

Fig. II - Statistical parsimony networks showing the phylogenetic relationships between ITS rRNA haplotypes of Steinernema feltiae. Numbers of nucleotide differences between the sequences are indicated on lines connecting the nodes

of Eastern Mediterranean. However, additional sampling is needed in this area to confirm the detection of 'basal' isolates of $S$. feltiae. The only strongly supported clade of $S$. feltiae both in the phylogenetic tree and in the spanning network was that consisting of European (including Sicilian) isolates and a single isolate from Siberia. All these isolates were characterised by ten nucleotide insertion in ITS1 rDNA. We can presume that this 
evolutionary event has happened outside the region of the Eastern Mediterranean.

Even on this preliminary stage of data collection, the similarity between Sicilian and Swiss S. feltiae is obvious. The nematodes of both isolates were collected in a mountainous area on different sides of the Apennine Peninsula characterised by different climatic conditions. Only additional sampling throughout Italy can reveal whether these isolates are represented by a haplotype widely distributed throughout the Apennines, or their distribution tends to mountainous areas.

The laboratory cultures of different isolates of $\mathrm{S}$. $\mathrm{fel}$ tiae demonstrate different abilities to invade the insect hosts and develop infective juveniles inside insect cadavers. In this sense, the study of the intraspecific variability of this EPN can be useful for its mass production and application. The general scheme of the haplotype diversity of this nearly cosmopolitan species of nematode can elucidate its evolutionary history and explain contemporary distribution patterns of EPNs. As the total number of nucleotide differences was quite low in the performed analysis of ITS rDNA region (maximal nucleotide difference between isolates was 19 bp between UK A2 isolate and those from Armenia and Belgium), data from other variable loci should be involved into the analysis as well. Thus further studies on the intraspecific genetic variability of entomopathogenic nematodes is needed.

\section{ACKNOWLEDGMENTS}

Research funded by the University of Catania Research Project 2020-22 of the Department of Biological Geological and Environmental Sciences: BINT (Biodiversity of insects, nematodes and tardigrades of Mediterranean environments)". Nucleotide sequence analysis was supported by RSF grant №19-74-20147 to S.E. Spiridonov.

\section{REFERENCES}

Altschul S.F., Gish W., Miller W., MYers E.W., LIPMAN D.J., 1990 - Basic local alignment search tool. - Journal of Mole-cular Biology, 215: 403-410.

BANDELT H., FORSTER P., RÖHL A., 1999 - Median-joining networks for inferring intraspecific phylogenies. - Molecular Biology and Evolution, 16: 37-48.

Clausi M., LONGO A., RAPPAZZO G., TARASCO E., VINCIGUERRA M.T., 2011 - Steinernema vulcanicum $n$. sp. (Rhabditida: Steinernematidae), a new entomo- pathogenic nematode species from Sicily (Italy). Nematology, 13: 409-423.

CLAUSI M., LEONE D., SPIRIDONOV S.E., VINCIGUERRA M.T., 2017 - Molecular characterisation of the new strain of Steinernema vulcanicum Clausi, Longo, Rappazzo, Tarasco \& Vinciguerra, 2011. - Russian Journal of Nematology, 25: 71-76.

CURRAN J., DRIVER F., 1994 - Molecular taxonomy of Heterorhabditis. In: COST 812: Biotechnology. Genetics of Entomopathogenic Nematode - Bacterium Complexes (A.M. Burnell, R.-U. Ehlers \& J.-P. Masson Eds). pp. 41-48. St Patrick's College, Maynooth, Co. Kildare, Ireland, European Commission.

HOLTERMAN M., VAN DER WURFF A., VAN DEN ELSEN S., VAN MEgEN H., Bongers T., Holovachov O., BAKKER J., HELDER J., 2006 - Phylum-wide analysis of SSU rDNA reveals deep phylogenetic relationships among nematodes and accelerated evolution toward crown clades. - Molecular Biology and Evolution, 23: 1792-1800.

Kumar S., Stecher G., TAMURA K., 2016 - MEGA7: molecular evolutionary genetics analysis version 7.0 for bigger datasets. - Molecular Biology and Evolution, 33: 1870-1874.

NGUYEN K.B., MARUNIAK J., ADAMS B.J., 2001 - Diagnostic and phylogenetic utility of the rDNA internal transcribed spacer sequences of Steinernema. - Journal of Nematology, 33: 73-82.

SPIRIDONOV S.E., REID A.P., PODRUCKA K., SUBBOTIN S.A., MoENS M., 2004 - Phylogenetic relationships within the genus Steinernema (Nematoda: Rhabditida) as inferred from analyses of sequences of the ITS1-5.8S-ITS2 region of rDNA and morphological features. - Nematology, 6: 547-566.

STOCK S.P., CAMPBELl J.F., NADLER S.A., 2001 - Phylogeny of Steinernema Travassos, 1927 (Cephalobina: Steinernematidae) inferred from ribosomal DNA sequences and morphological characters. Journal of Parasitology, 87: 877-889.

SWOFFORD D.L., 2003 - PAUP*. Phylogenetic Analysis Using Parsimony (*and Other Methods). Version 4.0b10. USA, Sinauer Associates.

THOMPSON J.D., GIBSON T.J., PLEWNIAK F., JEANMOUGIN F., HigGINS D.G., 1997 - The CLUSTAL_X windows interface: flexible strategies for multiple sequence alignment aided by quality analysis tools. - Nucleic Acids Research, 25: 4876-4882.

VRAIN T.C., WAKARCHUK D.A., LEVESQUE A.C., HAMILTON R.J., 1992 - Intraspecific rDNA restriction fragment length polymorphism in the Xiphinema americanum-group. - Fundamental and Applied Nematology, 15: 563-573. 